\title{
ALGUMAS TEMPESTADES ADENTRAM O PALÁCIO: CRISE, LEITURA E HISTORICIDADE EM TRÊS TRADUCOÕES DE MALLARMÉ Caroline MICAELIA ${ }^{1}$
}

de que maneira uma tradução quando entra na língua de chegada pode deslocar o corpo do que se escreve ali e refazer a roda de leitura e produção?” Marília Garcia, Um Teste de Resistores.

\footnotetext{
${ }^{1}$ Graduanda em Letras (Português/Francês) pela Universidade de São Paulo. Pesquisa o poeta Stéphane Mallarmé com auxílio da FAPESP (Fundação de Amparo à Pesquisa do Estado de São Paulo). É também tradutora, revisora e editora junto ao corpo editorial da Revista Cisma, de Crítica Literária e Tradução, da graduação em Letras - FFLCH/USP. Seu endereço de email é: carolinemicaelia@hotmail.com.
} 
RESUMO: Entre os últimos anos 1990 e os primeiros anos 2000 o curso interpretativo ligado à obra do francês Stéphane Mallarmé sofre uma leve perturbação: a valorização pela qual sua obra crítica passou nos últimos anos remodela, de certa maneira, não apenas o caminho percorrido pela recepção e pela tradução de seus trabalhos no Brasil, mas as próprias leituras que tem sido feitas, por toda parte, sobre o poeta. Em meio ao considerável fluxo de produções - nacionais e internacionais - que tocam essa reformulação crítica, os leitores brasileiros veem serem produzidas três traduções do mesmo texto mallarmeano "Crise de vers" (1987), com brevíssimo intervalo entre publicações. Este trabalho pretende produzir, a partir de uma leitura historicizante da obra de Mallarmé e de uma concepção do texto que o compreende como construção movente, uma breve análise-comparada entre os projetos tradutórios envolvidos na transposição do referido poema-crítico ao português, sugerindo as possibilidades de interpretação depreendidas de cada tradução, com o objetivo de propor um indicativo de reflexão acerca do interesse que a crítica brasileira tem demonstrado a propósito da crise de vers.

PALAVRAS-CHAVE: Mallarmé, Crise de vers, tradução, leitura, historicidade, crise.

\section{A FEW STORMS PENETRATE THE PALACE: CRISIS, READING AND HISTORICITY IN THREE TRANSLATIONS OF MALLARMÉ}

ABSTRACT: Between the late 1990's and the early 2000's, the interpretative course related to Stéphane Mallarmé's works passes through a slight disturbance: the appreciation by which his critical works have been through, the past few years, remodels, in a certain way, not only the patch crossed so far by the reception and the translation of his works in Brazil, but also the very readings that have being done all over the world about the poet. In the middle of a considerable flow of productions either national and international - concerning this new critical reformulation, brazilian readers watch the production of three translations of the same mallarmean text, "Crise de vers" (1987), with a brief period between publications. This paper intends to build, from a historicizing reading of Mallarmé's work and a conception that understands the text as a mutable construction, a brief comparative-analysis about the translating projects involved on the transposing of the critical-poem to portuguese, suggesting the possibilities of interpretation inferred from each translation, with the main goal being to propose an indicative for a reflexion on the interest distillate by the brazilian critic regarding the crise de vers.

KEYWORDS: Mallarmé, Crise de vers, translation, reading, historicity, crisis 
Carregando resquícios do que foram dois séculos das ressonâncias revolucionárias advindas do XVIII, a literatura francesa da conturbada década de 1940 ainda pensava encontrar nas revoluções do passado uma "doutrina da historicidade e um pensamento da política" (HAMEL, 2014: 64), conforme coloca Jean-François Hamel em seu Camarade Mallarmé : une politique de la lecture (2014). O caráter ainda romântico dessa tradição, longe de ser afastado pelas problemáticas em questão nos últimos anos da referida década, mais parece assombrá-los, impedindo que os terríveis acontecimentos desses anos pudessem ser lidos em outra chave que não a da lembrança de um tal passado. É nesse contexto, do ponto de contato entre o horror - la Terreur (HAMEL, 2014: 64) - da ocupação alemã na França durante a Segunda Guerra Mundial e os ainda presentes ares do passado revolucionário francês, que tem lugar o debate entre Maurice Blanchot e Jean-Paul Sartre a respeito da ideia de literatura engajada, do qual o protagonista será ninguém menos do que o poeta Stéphane Mallarmé.

A ideia de literatura engajada defendida por Sartre após o fim da Segunda Guerra implicaria um certo grau de responsabilidade e de comprometimento político que os escritores precisariam passar a ter em sua produção, especialmente em vista do que foi o cenário de tragédias relacionadas às ações dos regimes nazista $\mathrm{e}$ fascista europeus, e é claro, do enorme impacto que o período teve na França, então sob ocupação. De forma geral, Sartre acreditava que a construção de uma literatura pós-guerra que tivesse por missão a defesa da democracia caminhava na contramão do que tomou-se por um purismo em literatura, associado à figura de Mallarmé e de outros, tidos como influência direta para que os poetas entre-deuxguerres tivessem rompido com a sociedade e recusado a comunicação com seus contemporâneos. Reproposto por Blanchot, o problema da "autodestruição da linguagem" (HAMEL, 2014: 71) - ou mesmo da recusa na comunicação - ao qual esses poetas teriam sido vinculados, levaria Sartre a ponderar sua crítica a Mallarmé, reformulando-a no sentido oposto.

Blanchot vai ressaltar a necessidade do lugar de distinção que a arte deve ocupar frente ao mundo, vai dizer que a operação do poeta se dá através do mecanismo da recusa e que quando Mallarmé distingue a fala bruta ligada a isso que entende por "universal reportagem" 2 , suficiente para ensinar, narrar e descrever, da palavra essencial, que remunera o defeito das línguas (2003: 253), ele produz um movimento violento na linguagem: coloca-se contra a corrupção das palavras (HAMEL, 2014: 80), responsável por privar a comunidade de uma fala essencial3.

\footnotetext{
2 "universel reportage" (MALLARMÉ, 2003: 259).

${ }^{3} \mathrm{E}$ aí, naturalmente, há que se ressaltar a potência dessa "fala essencial" na poética de Mallarmé. Para se ter uma ideia, diz o poeta, em "Crise de vers": "As línguas imperfeitas no que muitas, falta a suprema: pensar sendo escrever sem acessórios, nem sussurros, mas tácita ainda a imortal fala, a diversidade, sobre terra, dos idiomas, impede que se profira as palavras que, não fosse isso se encontrariam, por um talhe único, ela mesma materialmente a verdade." (tradução minha para o trecho "Les langues imparfaites en cela que plusieurs, manque la suprême : penser étant écrire sans accessoires, ni chuchotement mais tacite encore l'immortelle parole, la diversité, sur terre, des idiomes empêche personne de proférer les mots qui, sinon se
} 
Para Blanchot, a obra de Mallarmé se apresentaria como ilustração de uma violência por parte da linguagem, como uma negatividade com origem no mal-estar revolucionário pós-século XVIII, isto porque sua recusa da comunicação consistiria num abalo no modus operandi da retórica como instrumento de transmissão sujeito ao domínio de quem ocupa os lugares de poder, uma recusa que se constitui no sentido de libertar a arte da submissão que a ela quiseram imprimir, que denuncia as ligações, historicamente construídas, entre a liberdade sem regras da linguagem e a liberdade desumana dos homens (HAMEL, 2014: 92). Diante da argumentação de Blanchot, Sartre reelaborará suas colocações, passando a entender a tarefa mallarmeana como um trazer à luz a impossibilidade de um engajamento por parte da literatura numa situação política como aquela na qual o poeta se encontrava em fins do XIX.

A discussão entre Sartre e Blanchot se envereda por outros caminhos que, em alguma medida, ainda terão em Mallarmé uma peça chave para o pensamento acerca de um engajamento na literatura dos últimos anos 40. O que nos interessa aqui, penso, não é exatamente entrar no mérito do que estava em questão para Sartre e para Blanchot ${ }^{4}$, mas antes perceber, a partir do reduzidíssimo relato acima esboçado, o quanto a obra de Mallarmé - ou mais precisamente, as leituras ${ }^{5}$ da obra de Mallarmé -, contribuíram para a construção dos discursos de uma época, e também para a construção da própria memória dos debates em questão naquele momento. Não só: o início de um esfacelamento da oposição entre uma "concepção autorreflexiva da literatura, pautada por uma busca infinita de sua essência em meio à agonia da experiência da linguagem, e uma concepção ativista, aberta à exterioridade eventual e revolucionária do mundo social" (HAMEL, 2014: 102, tradução minha) ${ }^{6}$ interessa enquanto potencialidade para a instauração de caminhos pelos quais poderão passar muitas das subsequentes leituras dessa obra; potencialidade não só ligada ao que os escritos de Mallarmé dizem sobre nosso presente, mas também a uma possível configuração - suscetível a outras tantas reconfigurações - da compreensão que temos no tocante ao que então poderia estar em jogo para o poeta.

trouveraient, par une frappe unique, elle-même matériellement la vérite"). Para Mallarmé, no mesmo trecho, o verso "filosoficamente remunera o defeito das línguas, complemento superior" (MALLARMÉ, 2003: 252).

${ }^{4}$ Discussão que, aliás, já se esboça no belo ensaio que Marcos Siscar escreve sobre o porquê de se reler Mallarmé hoje, intitulado "O túnel, o poeta e seu palácio de vidro". Cf. SISCAR, Marcos. Poesia e Crise. Campinas: Editora da Unicamp, 2010.

${ }^{5}$ Há aqui alguma graça em tratar as aparições deste termo, no decorrer do artigo, em seu múltiplo sentido.

6 "une conception auto-réflexive de la littérature, arquée sur la poursuite infinie de son essence à travers l'angoisse de l'expérience langagière, et une conception activiste, ouverte à l'extériorité événementielle et révolutionnaire du monde social." (HAMEL, 2014: 102) 
Não é demais ressaltar que, embora estivesse muito ligada à tradição, a obra de Mallarmé possui uma eminência de futuro (num certo sentido, um deslocamento em relação ao seu próprio tempo, ou ainda, se quisermos, uma espécie de projeção para as décadas seguintes) que incomodava, inclusive, muitos de seus contemporâneos7; se, entretanto, nos lembrarmos da ilustração que Walter Benjamin apresenta, em "Notes sur le Tableaux parisiens de Baudelaire", há algum interesse em pensar obras como as de Baudelaire ou de Mallarmé "como um tipo de chave, confeccionada sem a menor ideia da fechadura em que um dia ela poderia ser introduzida" (BENJAMIN, 2000: 119, tradução minha) ${ }^{8}$. Daí também a relevância de ter em conta, para uma reflexão sobre ambos os movimentos anteriormente mencionados - o de ler o presente no passado e o de ler o passado no presente (HAMEL, 2014: 15) -, não só a obra do poeta em si, mas os sucessivos modos de compreensão relativos a ela ao longo dos anos; cabe, ademais, colocar que os próprios atos de leitura e de interpretação constituem, do mesmo modo, atos de memória, fundamentais à compreensão - ou melhor, a certo 9 tipo de compreensão - a respeito do texto, salvo quando aí jogados, preto no branco, dando início a um processo inevitável de cristalização que vai, consequentemente, conduzir a leitura do texto ao anacronismo.

A validade de refletir sobre a obra de Mallarmé - e, aliás, sobre a de qualquer outro escritor consagrado ou em vias de consagração, parte constitutiva de uma memória cultural largamente compartilhada (HAMEL, 2014: 35) - sob tais premissas mora a ideia, muito cara a autores como Henri Meschonnic ${ }^{10}$, de que um texto só existe quando lido, ou seja, de que o texto se reconfigura a cada leitura já que as próprias condições de leitura mudam. Em suma, ele não é o mesmo em momentos históricos diferentes, não só pelas transformações de ordem sóciopolítico-filosóficas, mas também pelas de ordem linguística; ele não é o mesmo se lido por pessoas de estratos sociais diferentes, de gêneros diferentes, de idades diferentes e, em geral, com experiências de vida diferentes; ele não é o mesmo se lido em lugares diferentes, por pessoas de nacionalidades distintas; e, por conseguinte, ele certamente não é o mesmo quando traduzido para línguas diversas daquela em que primeiro habitou.

\footnotetext{
7 Entre os quais Degas, segundo menciona Fernando Scheibe, no texto introdutório de seu Divagações (2010): "conta-se que foi durante sua conferência [de Mallarmé] - 'mesmo oração fúnebre' sobre Villiers de l'Isle Adam, proferida em 1890 no salão de Berthe Morisot, que Degas saiu revoltado, exclamando: - 'Não compreendo nada disso, nada!'." (MALLARMÉ, 2010: 11)

8 "comme une sorte de clé, confectionée sans la moindre idée de la serrure où un jour elle pourrait être introduite" (BENJAMIN, 2000: 119).

${ }^{9}$ Que não só pretende ler o texto, mas também seu movimento, como discutirei na sequência.

${ }_{10}$ Menciono Meschonnic, neste trecho, pois que as noções de "historicidade radical da linguagem", "oralidade" e "ritmo" que o autor desenvolve em Linguagem, ritmo e vida - e que exigiriam um outro ensaio para que fossem abarcadas com a complexidade que lhes é de direito permeiam a ideia sobre a qual discorro neste parágrafo (2006: 10, 15, 36, 43 et seq.).
} 
Entendendo nessa ideia um dos pressupostos latentes ${ }^{11}$ para a construção de um debate a respeito da questão da voz. Roberto Zular colocará que o texto não é, portanto, estanque, mas movente, e que sua permanência vincula-se de maneira intrínseca a um contínuo - visualmente, a uma fita de möbius - entre instabilização e estabilidade; ele produz uma ontologia variável (2014b: 73) que se mantém em ressonância. Seguindo esse esquema, ler um texto significaria, então, ler o ritmo das transformações desse texto, ou seja, produzir uma intersecção, um campo possível de sentido entre o que se entende por autonomia do texto literário e o que é tido por variabilidade ontológica. $\mathrm{O}$ modo como a dimensão textual se resolveria com a dimensão histórica abre assim um precedente para que, desde a possibilidade de estanciar uma tensão, uma enunciação se produza ${ }^{12}$; em outras palavras, encontrar uma maneira de escapar ao tudo ou nada envolvido no lance entre essas duas dimensões pode passar, justamente, por um lugar em que a diferença entre elas seja produtiva, em que a leitura do texto seja também a leitura do ritmo das transformações que o atravessam, em que o caráter performativo do texto não se perca, fazendo com que seus modos de funcionamento passem a operar sob a égide de uma experiência rígida. Nas palavras de Zular, penetradas por sua leitura de "O mármore e a murta" (2002), do antropólogo Eduardo Viveiros de Castro, ler seria também - e especialmente em se tratando de Brasil - uma experiência corporal:

(...) pensar os textos como a construção estrutural de uma multiplicidade de posições em uma mesma voz que poderia ser ocupada por diversos corpos, como se um poema fosse uma espécie de pele que pudesse ser vestida por muitas pessoas, como se o poema produzisse outra voz na nossa voz, como se lêssemos para produzir essa diferença intensiva na própria voz. ( 2014b: 71)

Analogamente, o que está em jogo no ato de traduzir - e entendendo a tradução não só no que toca o âmbito de seu fazer artístico, mas mesmo como gesto crítico, jamais dissociado de um gesto interpretativo - é, rigorosamente, a objetivação de uma ressonância, e mais: o modo como, em meio a tal objetivação, a movência da língua encontra a movência do texto. Em tradução, estar atento ao ritmo das transformações do texto de partida significa visualizar, como numa fotografia de Henri Cartier-Bresson, a diferença entre o que veio antes e o que virá depois, posto que o elemento de estranheza que torna a obra algo extraordinário àquele momento da língua e do texto - e, certamente, ao momento no qual encontravam-se a língua e o

11 Os outros dois relacionar-se-iam às ideias de Émile Benveniste e Paul Zumthor - respectivamente, sobre "voz como lugar de enunciação" e sobre "vocalidade e performance" -, de certa maneira também subentendidos aqui.

12 Sobre isso, Zular dirá ser através da voz que conseguimos conflagrar a possibilidade da existência dessa enunciação que se produz a partir de uma tensão pois que a voz que estabelece essa "divisão paradoxal" é também ela capaz de instaurar um limiar entre essas oposições (ZULAR, 2014a: 76). 
texto quando da origem da obra - duplica-se na ocasião de sua tradução; nas palavras de Antoine Berman em A prova do estrangeiro (2002), "a estranheza nativa da obra se redobra de sua estranheza (efetivamente acrescida) na língua estrangeira" (2002: 22). Num sentido parecido, quando Meschonnic nos diz, em seu Poética do traduzir (2010), que "o ritmo, organização do movimento da palavra na escritura, é então a unidade de equivalência numa poética da tradução" (MESCHONNIC, 2010: 63) ${ }^{13}$, o que imediatamente se coloca em evidência é uma noção dialética e viva do ato de traduzir - e do próprio texto -, responsável por permitir uma distinta aproximação à obra, um acesso a ela de uma ordenação outra.

Traduzir teria a ver, pois - e ainda considerando as colocações de Zular -, com estar na lógica da metonímia: há que se escolher, entre linhas de força, um caminho pelo qual seguir - um projeto ${ }^{14}$. $\mathrm{E}$ isto significa dizer, em última instância, que a objetivação dessa ressonância que é o texto não acontece ao acaso, mas passando, antes, pela eleição, entre um leque de possibilidades, dos aspectos que, para o tradutor e para a época em que se produz o texto de chegada - sem que aquele perca de vista a historicidade do texto de partida -, pareçam mais expressivos. De tal maneira - e aí replicando num senso todo outro o movimento produzido por Sartre e Blanchot na França dos anos 40 -, faz-se pertinente pensar as implicações de uma leitura que se construa não a partir da produção de um texto crítico ipsis literis - ou de textos críticos -, mas da produção de uma tradução (que por si só já parte de uma leitura), ou ainda melhor, a partir de um conjunto de traduções diversas da obra de um mesmo autor ${ }^{15}$. E se, nesse caso, as consequências dessa leitura já parecem de antemão valiosas, o que pensar de uma que esteja apoiada em várias traduções do mesmo texto de um autor, com o adendo de terem sido todas produzidas por tradutores diferentes e publicadas num irrisório intervalo de tempo entre uma e outra? Esta suposição, por mais peculiar que pareça, corresponde a uma das nuances que compõem o quadro da recepção e do pensamento crítico sobre a obra de Mallarmé no Brasil dos primeiros anos do século XXI ${ }^{16}$.

O poema-crítico "Crise de vers" (1897), um dos textos fundamentais de Mallarmé e ponto central para a construção dos discursos em torno da referida nuance, discutirá uma irritação conflituosa no verso, evidenciada com a morte de Victor Hugo - ou com aquilo que ela simbolizava: o fim de um ciclo histórico do verso, uma espécie de libertação ou reconquista do que havia sido interditado pela auto-

\footnotetext{
${ }^{13}$ Parece aqui produtivo mencionar, para uma compreensão mais ampla dos problemas tratados por Meschonnic que, em algumas das traduções de sua obra ao português, o termo "palavra", do francês "parole", foi traduzido por "voz", como é o caso em: MESCHONNIC, Henri. Linguagem, ritmo e vida. Tradução de Cristiano Florentino. Belo Horizonte: FALE/UFMG, 2006. p. 43. Com esse mesmo intuito, Álvaro Faleiros, em sua leitura deste texto, lembrou que a tradução por "fala" é também produtiva, especialmente se tivermos em conta que Meschonnic era um grande leitor de Benveniste.

${ }^{14} \mathrm{E}$ de forma alguma, vale ressaltar, um relativismo que a tudo outorgaria status de validade.

${ }^{15}$ Como faz Álvaro Faleiros, em "Três Mallarmés: traduções brasileiras". Cf. FALEIROS, Álvaro. "Três mallarmés: traduções brasileiras". In: Aletria (UFMG), v. 22, 2012. p. 17-31.

16 Álvaro Faleiros, no ensaio previamente mencionado, chamará o momento de "terceiro Mallarmé" (FALEIROS, 2012: 26).
} 
ridade de um único grande poeta: a possibilidade, não só de se expressar, mas de se modular. No texto, Mallarmé serve-se de um uso idiossincrático da pontuação, bem como da infração de algumas regras básicas da língua - permitindo a queda de elementos funcionais e rompendo com a associação entre sujeito, verbo e complemento (SISCAR, 2010: 97) -, para, por meio desta estratégia retórica ligada à fragmentação e da inserção de si mesmo numa posição de "testemunha da aventura" (MALLARMÉ, 2003: 249, tradução minha) ${ }^{17}$ empreendida pelo verso livre simbolista, observar a mencionada perturbação no verso e propor um diagnóstico a respeito do estado de crise no qual o verso livre lança as concepções tradicionais da poesia; o poeta formula também uma teoria crítica do verso, da qual a modernidade excederia em muito o momento próprio do simbolismo. Na construção de "Crise de vers", junta-se à peculiaridade no uso da pontuação "o risco constantemente assumido do paradoxo entre o jorro e a contenção, transformando frases acessórias em apostos, expressões explicativas e palavras isoladas em termos com valor metafórico ou conceitual" (SISCAR, 2010: 97); arte de continuidade e corte que caracteriza não só a prosa mallarmeana, mas também o modo como o poeta por vezes delineia sua própria prática de versificação.

Tendo sido já muito referenciado na produção de Haroldo de Campos, Augusto de Campos e Décio Pignatari ao longo dos textos que teceram e acompanharam o desenrolar do programa vanguardista da poesia concreta, o poema-crítico de Mallarmé só vai ganhar sua primeira tradução ao português no ano de 2008, quando Ana de Alencar publica seu "Crise do verso", no número 20 da revista Inimigo Rumor. Simultaneamente ao processo dessa publicação (entre os anos de 2007 e 2010), Marcos Siscar apresenta em seminários e publica, no primeiro volume da revista Modo de Usar \& Co. (2009), o célebre ensaio "Poetas à beira de uma crise de versos", no qual desenvolve uma das questões fundamentais do texto de Mallarmé - assunto que aparece desde o título - dialogando diretamente com a tradução de Alencar no que toca sua opção por "Crise do verso", e não "Crise de verso" ou "Crise de versos" que, de acordo com o autor, seriam títulos mais alinhados ao projeto poético mallarmeano. O último dado de publicação do ensaio de Siscar data de 2010, com o lançamento de seu livro/compilação de ensaios Poesia e Crise, no qual, vale lembrar, há também um texto importante sobre as traduções de Mallarmé, intitulado "Traduzir Mallarmé é o lance de dados", além de outro, "O túnel, o poeta e seu palácio de vidro"18, especialmente sobre a publicação da primeira tradução completa de Divagations (1897), por Fernando Scheibe, livro que abarca a prosa crítica de Mallarmé - incluindo "Crise de vers" -, sob o título de Divagações (2010), entre as quais "Crise de verso". No mesmo ano de 2010, Gilles Abes publica sua própria colaboração: seu "Crise de verso", introduzido por um texto

17 "témoin de cette aventure" (MALLARMÉ, 2003: 249).

18 Vale mencionar que tanto "Traduzir Mallarmé é o lance de dados" como "O túnel, o poeta e seu palácio de vidro" foram também publicados, respectivamente, na tradução de Álvaro Faleiros para o seminal Um lance de dados (2013) e na tradução de Fernando Scheibe para o Divagações (2010). 
crítico de título "Uma tradução de 'crise de verso' de Mallarmé: a ótica do enigma como símbolo do texto literário", encerrando, até o presente momento, o encadeamento dos eventos ligados ao referido texto.

O interessante é que, considerada a proximidade entre os anos de publicação, as traduções de Alencar, Scheibe e Abes apresentam maneiras de ler Mallarmé muito diferentes entre si, indicadas desde as próprias escolhas lexicais feitas por cada autor até o modo como cada um lida com as dificuldades entranhadas na prosa do poeta francês, a qual, como nos lembra Dirceu Villa, em estudo inédito, reflete "a exigência de sua técnica [que] se combinava de modo indissociável a uma profunda elaboração mística do discurso, e é assim que o próprio Mallarmé falava de si como syntaxier, ou poeta de virtude sintática" Na tradução de Alencar, por exemplo, parece estar em pauta uma compreensão muito particular do modo como a sintaxe mallarmeana poderia abraçar a língua portuguesa, o que resulta, muitas vezes, em construções radicalmente diferentes das propostas pelos outros tradutores, caso do trecho "que vers il y a sitôt que s'accentue la diction, rythme dès que style", que Alencar traduz por "de que há verso tão logo acentuada a dicção, ritmo tão logo estilo", enquanto Scheibe opta por "que verso há tão logo se acentua a dicção, ritmo desde que estilo" e Abes por "que verso há tão logo se acentua a dicção, ritmo tão logo estilo". A proposta de Alencar, nesse caso, se realiza através de um processo de racionalização, "recompondo as frases e sequências de frases de maneira a arrumá-las conforme uma certa ideia da ordem de um discurso" (BERMAN, 2007: 48) ${ }^{19}$, o que conduziria a arborescência do texto de partida a uma linearidade que lhe seria pouco familiar.

Um outro exemplo desse movimento pode ser encontrado quando nos deparamos com o trecho "le besoin de poétiser, par opposition à des circonstances variées, fait, maintenant, après un des orgiaques excès périodiques de presque un siècle comparable à l'unique Renaissance, ou le tour s'imposant de l'ombre et du refroidissement, pas du tout ! que l'éclat diffère, continue", traduzido por Alencar como "agora, após um desses orgíacos excessos periódicos de quase um século comparável ao único Renascimento, ou o retorno que impõe a sombra e o arrefecimento, a necessidade de poetizar, por oposição a circunstâncias variadas, faz com que nada o resplendor difira, continua", por Scheibe como "a necessidade de poetizar, por oposição a circunstâncias variadas, faz, agora, após um dos orgíacos excessos periódicos de quase um século, comparável à única Renascença, ou a vez se impondo da sombra e do resfriamento, de modo algum! que o brilho difere, continua" e por Abes como "a necessidade de poetizar, por oposição a circunstâncias variadas, faz, hoje, após um dos orgíacos excessos periódicos de quase um século comparável ao único Renascimento, em que o tour se impondo da sombra e do esfriamento, de forma alguma! que o

${ }^{19}$ Segundo Berman, uma das tendências deformadoras dos textos, que aparecem em toda a tradução (a questão aqui diz respeito a toda a tradução como em "toda e qualquer tradução", e não apenas àquelas estudadas neste artigo, por isso mantenho "em toda a tradução"), impedindo-lhe de atingir seu verdadeiro objetivo. 
resplendor difere, continue". A ordem elaborada por Alencar, nesse caso, para além de comprometer a arborescência do excerto, atribui destaque a um elemento que, no texto de partida, aparece mais como mediador: ora, se a ênfase do trecho parece estar na relevância que o então novo momento da necessidade de poetizar teria em relação à tradição desta necessidade, em outras palavras, no fato de que o momento então atual não deixaria nada a desejar para a tradição ("pas du tout ! que l'éclat differe, continue"), a ênfase dada por Alencar parece estar, ao contrário, justamente no realce da tradição em relação ao novo momento. Pode se dizer que a solução sugerida pela tradutora, ao reordenar os períodos do referido trecho, aponta para uma argumentação menos conciliadora do que aquela adotada por Mallarmé no texto em questão.

Não obstante, na tradução de Alencar podem ser encontradas, também, escolhas lexicais que, apesar de parecerem ter um eco, ainda que já bastante distante, das leituras dos concretos, não seguem exatamente essa busca por "recursos expressivos e soluções 'válidas' em português", a qual Álvaro Faleiros, no texto introdutório para a mais recente tradução de "Un coup de dés jamais n'abolira le hasard" (1974), também realizada por ele, descreve como prática corrente dessa poética do traduzir, mas precisamente uma busca por soluções que em alguma medida se alinham à tradição de leitura desse texto - a saber, a uma tradição que muitas vezes trata o poeta tomando por base o problema do "hermetismo", a rejeição da vida e da realidade, à qual ele foi associado. Um bom exemplo disso encontra-se logo no início do texto, no uso que Mallarmé faz do termo "brochures", que Alencar traduzirá para "opúsculos", enquanto os outros dois preferirão "brochuras". O afastamento que o texto de Alencar produz em relação ao de Mallarmé, em decorrência da racionalização sintática e do enobrecimento ${ }^{20}$ lexical, apresentase, entretanto, de forma coesa ao longo de todo o projeto: a sintaxe e o léxico, apesar de não se alinharem estritamente ao texto mallarmeano, parecem ter influência desse tom que Alencar, em sua "nota do tradutor", diz ser "toda uma entonação do registro falado nesse texto tão trabalhado" (2008: 163). Características como essas, que parecem brincar com o tom de "conferência" - que, aliás, grande parte dos fragmentos de fato possui ${ }^{21}$-, em conjunto com a ideia de que a própria personificação do verso, Victor Hugo, não é apenas um poeta mas também um político, trazem à tona não só a crise do verso como crise de um modo de articulação, mas a crise em que então se encontravam as próprias relações público-privadas, com a questão operária, a onda anarquista, o anticlericalismo (ALENCAR, 2008: 163); adversidades que não parecem fechadas em si mesmas, sem gerarem consequências para a linguagem e sem serem atingidas por uma crise na linguagem. Em suma, o texto de Alencar parece então convergir, justamente, para as implicações

20 Outras duas tendências deformadoras das quais fala Berman.

${ }^{21}$ Alguns dos fragmentos que compõem "Crise de vers" foram efetivamente apresentados por Mallarmé em conferências nas universidades de Oxford e de Cambridge. 
de uma crise do verso, e mesmo para o grau de alcance que uma perturbação na própria forma do verso poderia produzir.

Em comparação com a tradução de Alencar, a de Scheibe constrói-se de maneira muito mais alinhada ao texto de Mallarmé, incorrendo, por vezes, num alinhamento até extremo, que acarretaria a ocorrência de ruídos produzidos no texto de chegada, de modo a provocar uma sensação artificial que de maneira alguma se ligaria ao "registro falado" do qual trata Alencar. Exemplificando: no trecho inicial do texto, quando Mallarmé diz "tout à l'heure, en abandon de geste, avec la lassitude que cause le mauvais temps désespérant une après l'autre après-midi, je fis retomber, sans une curiosité mais ce lui semble avoir lu tout voici vingt ans...", Scheibe propõe, para a parte final, a solução "mas parece-lhe ter lido tudo eis já vinte anos...", enquanto Alencar escreve "mas como se houvesse lido tudo há vinte anos..." e Abes, por sua vez, "mas parece ter lido tudo há vinte anos". O estranhamento causado pelo pronome oblíquo "lhe" - que, em português, indica a presença de uma terceira pessoa -, diz respeito ao fato de que o uso da terceira pessoa do singular, no francês, configura muitas vezes apenas uma não manifestação de sujeito, e não propriamente a existência de uma terceira pessoa: diferentemente do português, $o$ francês, como o inglês, requisita a presença do sujeito mesmo para frases como "il pleut", que em português seria simplesmente "chove". Um outro exemplo desse problema pode ser observado em "témoin de cette aventure, où l'on me voulut un rôle plus efficace quoiqu'il ne convient à personne...", que Scheibe traduz para "testemunha dessa aventura, em que me quiseram um papel mais eficaz ainda que ele não convenha a ninguém...", Alencar para "testemunha de tal aventura, em que me quiseram um papel mais eficaz, embora não coubesse a mais ninguém..." e Abes para "testemunha desta aventura, em que me quiseram um papel mais eficiente se bem que não convenha a ninguém...".

Num outro sentido, o teor dessa preocupação com a similaridade em relação ao texto de partida também provoca estranhamento nos momentos em que, havendo uma palavra como "voler", que em francês pode significar tanto "voar" como "roubar", Scheibe preocupa-se em costurar, em meio ao texto, as duas opções, sem menção de optar por uma ou por outra, como indica o trecho "(...) et statue du mointre effort pour simuler la versification, à la manière des codes selon quoi s'abstenir de voler est la condition par exemple de droiture", de Mallarmé, que Scheibe vai transpor em "(...) e estatui o menor esforço para simular a versificação, à maneira dos códigos segundo os quais se abster de roubar/voar é a condição por exemplo de retidão". Ainda que num primeiro momento essa necessidade de tudo dizer pareça atropelar - e, em última análise, acabe atropelando - a economia do texto, há certo interesse em pensar que ela está afinada ao projeto tradutório de Scheibe, haja vista sua compreensão de que as palavras do texto mallarmeano "nos intimam a devir, bem mais do que nos incitam a compreender" (MALLARMÉ, 2010: 9), conforme a epígrafe de Paul Valéry, que introduz o texto de apresentação de Divagações. Com uma proposição como esta Scheibe parece pretender um pen- 
samento mais filosófico acerca da produção do poeta, compreendendo, como Siscar, que o texto não trata de uma crise do verso enquanto forma, mas da evidência, em meio à busca de um pensamento sobre as possibilidades políticas da poesia (MALLARMÉ, 2010: 10), de que esta crise se estabelece como manifestação não somente de um contexto, mas de um discurso (de um projeto e de uma retórica) da época moderna (SISCAR, 2010: 112).

Partindo de um pressuposto parecido com o de Scheibe no que toca esse "devir" valéryano ${ }^{22}$, mas utilizando-se de mecanismos outros, Abes também se preocupa com a polissemia de alguns dos termos utilizados por Mallarmé e, a despeito da crítica que faz a Ana de Alencar, muito se vale dos dois projetos para entrançar os arranjos de seu "Crise de verso". Para Abes, os elementos da escrita mallarmeana desvelar-se-iam nas entrelinhas do texto, "como símbolos que formam a tessitura invisível e impenetrável do enigma"23 (ABES, 2010: 153), o qual seria o cerne das escolhas do tradutor, de modo que o que parece estar em jogo neste texto seria antes as possibilidades teóricas para uma tradução da prosa de Mallarmé do que o "Crise de vers" em si. O trabalho do tradutor, neste terceiro projeto que circunda o texto do poeta francês, leva a compreensão da tradução como gesto crítico a um limite: muitas vezes as soluções não se resolvem unicamente no enlaçar do texto poético, fazendo com que a polissemia precise ser transmitida através de uma nota de rodapé, como na passagem em que Mallarmé escreve "la littérature ici subit une exquise crise, fondamentale", que Abes resolve com "a literatura aqui sofre uma requintada crise, fundamental", explicando, ao pé da página, que

em francês: "une exquise crise". O adjetivo "exquis" significa, ao mesmo tempo, delicioso, raro, sutil. Houve grande dificuldade em se encontrar termo equivalente. Escolhemos, então, o termo "requintada", por parecer abarcar sentidos próximos ao adjetivo em francês. (2010: 165)

Cabe colocar que, de certa forma - e malgrado algumas de suas críticas a Alencar irem exatamente nesse sentido - o movimento aí caminha justo na direção de um esclarecimento do texto mallarmeano, pois, em vez de propor uma solução que possa dar conta da multiplicidade de sentidos depreendidos pelo termo "exquise", dissolve-o, antes, em possibilidades, abrindo-o para leituras e, no entanto, aliviando um mecanismo de funcionamento próprio do texto de Mallarmé, a saber, uma espécie de significação tensa, potencial, ou, como bem percebe Abes, enigmática. E ainda que o tradutor opere aí justo no sentido oposto de uma das premissas

22 Que Abes chamará "sugestão" (ABES, 2010: 152). Qualquer que seja a nomenclatura empregada ou a ênfase dada para discutir esse procedimento, não parece demasiado lembrar que ele estaria, num primeiro momento, estreitamente ligado à noção de "símbolo", de onde deriva o nome do movimento estético em que Mallarmé tem sido inserido através dos anos e do qual teria sido mestre.

${ }^{23} \mathrm{O}$ enigma, para Blanchot, teria por fonte " o vazio, a falta, que é o objeto da criação" (Apud BLANCHOT, 2010: 149). 
de seu próprio projeto tradutório, a contradição, neste caso, não parece se apresentar como grande problema, isto porque o próprio Abes, em certo momento de seu ensaio, menciona fazer opção pelo rodapé "por mais que Umberto Eco veja nisso uma prova de fracasso da parte do tradutor." (2010: 162) Com efeito, localizando-se muito mais próximo de um trabalho ligado à prática da retradução, à pesquisa teórica, a um pensamento sobre possíveis maneiras de traduzir que possam estar em consonância com um texto de Mallarmé, a empreitada percorrida por Abes dá margem a práticas mais elucidativas - ainda que ele reitere mais de uma vez o fato de que sua compreensão a respeito da obra do poeta francês volteia a imagem do "enigma"; ela conflagra os dois primeiros projetos, reverenciando criticamente o interesse de suas escolhas e visitando, de sua parte, outra trilha viável rumo ao seu próprio lugar, junto às demais, na criação de uma coreografia possível para pensar-encenar esse texto.

Conforme lembra Álvaro Faleiros, em "Refrações sobre um lance de dados de Mallarmé" (2013), Meschonnic considera que uma boa tradução é aquela que "em relação com a poética do texto inventa sua própria poética e que substitui as soluções da língua pelos problemas do discurso, até inventar um novo problema como a obra inventa" (MALLARMÉ, 2013: 35); e são precisamente estes os desdobramentos em evidência na ocasião do fenômeno ligado a sucessivas traduções que, num interstício de mais ou menos meia década, acrescentou mais lenha à fogueira do já crescente interesse pela obra de Mallarmé24. Floresce, dessas versões do "Crise de vers" no Brasil, um debate engendrado por conversas caras à recepção da obra mallarmeana, à historicidade das traduções dessa obra ao português, à prática brasileira da retradução e até mesmo ao projeto autoral de Mallarmé, em conjunto com as consequências de pensar no que significa, hoje, reler a obra do poeta - especialmente estando no Brasil -, isto porque, como coloca Villa, "parte da ideia de jogo é o poder remontar-se a cada nova jogada, e Mallarmé estava perfeitamente ciente desse aspecto de sua obra". Resumidamente, nas palavras de Faleiros, desta vez em "Três Mallarmés: traduções brasileiras" (2012):

num período de poucos anos, "Crise de vers" passa a circular em duas [agora três] traduções que se encontram no centro de um processo de ressignificação e ampliação da recepção da obra de Mallarmé no Brasil, cuja prosa e crítica hoje circulam amplamente e fazem parte de debates não

24 Impulsionado, na França, pelo início da republicação de sua obra completa na coleção Pléiade, por Bertrand Marchal (1998), decorrência do centenário da morte de Mallarmé, e no Brasil, pelos trabalhos sobre tradução produzidos por Ana Cristina Cesar no fim dos anos 1980, além de diversas traduções da obra do poeta - com destaque para sua prosa -, realizadas por diversos tradutores no curso dos anos 1990. 
mais mediados exclusivamente por princípios formalistas ou discursos de vanguardas. 25 (2012: 28)

Da tradição de leitura ligada ao poema-crítico, Ana de Alencar expande a problemática da forma às marcas da retórica, dando abertura, talvez, para um pensamento sobre o lugar da voz na poética deste autor tido como o extremo do escrito, um pensamento sobre a extensão de lugares que um abalo da ordem de uma crise na linguagem poderia atingir. Do questionamento sobre os âmbitos da crise e sobre os modos como ela estaria ligada não somente à configuração do verso da tradição, mas a um lugar fundador da poesia e a um ímpeto que rege a modernidade, Fernando Scheibe retrabalha as proposições historicamente ligadas a esse texto, deslocando-as para uma outra realidade possível de sentido. Do recém iniciado debate sobre as possibilidades e potencialidades de uma crise do verso ou de uma crise de verso, Gilles Abes realça a necessidade de pensar, a partir do percurso da teoria literária, a importância de conservar o tom de sugestão que estaria envolvido na polissemia e nas entrelinhas implícitas no caráter enigmático presente em alguns momentos da produção do poeta francês. Desse ritmo que permeia o jogo das leituras, desses flexíveis entroncamentos entre elas e dessas discussões que tais leituras despertam, a maior prova de que a obra de Mallarmé não permanece sob um estado de eternidade, mas se eterniza porque permanece viva; metamorfoseia-se, permitindo que cada um a decifre à luz de representações coletivas aos poucos interiorizadas, das quais se desenlaçam diferentes maneiras de dizer e de fazer.

Como bem coloca Hamel, a historicidade de uma obra não se reduz a uma data, nem a uma época, muito menos a um movimento estético - e, eu acrescentaria, também não se reduz simplesmente ao lugar ou à língua que originou essa obra. Na junção de cada nova leitura à concatenação da memória, os contornos externos da obra se deslocam, enquanto sua arquitetura interna se remaneja (HAMEL, 2014: 19). E é porque a leitura fabrica, a partir de textos esparsos, a identidade histórica de uma comunidade, que, quando pensados em sua historicidade, debates como o de Sartre e Blanchot, ou mesmo como o que emoldura o quadro das traduções brasileiras do "Crise de vers", não tornam anacrônicas as grandes obras do passado: colocam-nas em movimento: tiram-nas do confortável trono em que a passagem do tempo insiste acomodá-las: abrem as janelas do palácio para que novos e outros ares - quem sabe até algumas tempestades, como bem gostaria Mallarmé - passem a circular, desobstruindo a respiração e levantando a assentada poeira do tempo.

${ }^{25}$ No trecho, o autor se refere às traduções de Alencar e de Scheibe. 
ABES, Gilles. "Uma tradução de 'Crise de verso' de Mallarmé: a ótica do enigma como símbolo do texto literário". In: TradTerm, 16, 2010. p. 149-174.

ALENCAR, Ana de. "Crise do verso". In: Inimigo Rumor, n.20. Rio de Janeiro: 7Letras, 2008.

BENJAMIN, Walter. Le surréalisme. Le dernier instantané de l'intelligentsia européenne. Traduction de M. de Gandillac, Oeuvres, II. Paris : Gallimard, Coleção Folio, 2000.

BERMAN, Antoine. A prova do estrangeiro: cultura e tradução na Alemanha romântica: Herder, Goethe, Schlegel, Novalis, Humboldt, Scheleiermacher, Hölderlin. Tradução de Maria Emília Pereira Chanut. Bauru: EDUSC, 2002.

. A tradução e a letra, ou, O albergue do longínquo. Traduzido por Marie-Hélène Catherine Torres, Mauri Furlan e Andréia Guerini. Rio de Janeiro: 7Letras/PGET, 2007.

FALEIROS, Álvaro. "Três mallarmés: traduções brasileiras". In: Aletria (UFMG), v. 22, 2012. p. 17-31.

HAMEL, Jean-François. Camarade Mallarmé. Une politique de la lecture. Paris : Les Éditions de Minuit, Coleção Paradoxe, 2014.

MALLARMÉ, Stéphane. "Crise de vers". In: Igitur ; Divagations ; Un coup de dés. Présentée, établie et anotée par Bertrand Marchal. Paris : Gallimard, 2003.

Divagações. Tradução e apresentação de Fernando Scheibe. Florianópolis: Editora da UFSC, 2010.

. Um lance de dados. Introdução, organização e tradução por Álvaro Faleiros. Cotia: Ateliê Editorial, 2013.

MESCHONNIC, Henri. Linguagem, ritmo e vida. Tradução de Cristiano Florentino. Belo Horizonte: FALE/UFMG, 2006.

. Poética do traduzir. Tradução de Jerusa Pires Ferreira e Suely Fenerich. São Paulo: Perspectiva, 2010.

SISCAR, Marcos. Poesia e Crise. Campinas: Editora da Unicamp, 2010. 
ZULAR, Roberto. Apresentação. In: Literatura e sociedade (FFLCH/USP), v. 18, 2014a.

Apresentação. In: Literatura e sociedade (FFLCH/USP), v.

19, 2014b. 